\title{
Exosomes in Sepsis Diagnosis and Treatment
}

\author{
Min Huang1* Huan Deng1 ${ }^{*}$, Jiang Li², Xingyu Tao' ${ }^{1}$ Baohui Jia ${ }^{3 \#}$ \\ ${ }^{1}$ The Third Affiliated Hospital of Nanchang University, Nanchang, China \\ ${ }^{2}$ Zhengzhou Railway Vocational and Technical College/Henan Provincial Engineering Research Center of Natural Drug \\ Extraction and Medical Technology Application, Zhengzhou, China \\ ${ }^{3}$ The Fourth Affiliated Hospital of Nanchang University, Nanchang, China \\ Email: "bhjia@126.com
}

How to cite this paper: Huang, M., Deng, H., Li, J., Tao, X.Y. and Jia, B.H. (2019) Exosomes in Sepsis Diagnosis and Treatment. International Journal of Clinical Medicine, 10, 565-575.

https://doi.org/10.4236/ijcm.2019.1010046

Received: September 9, 2019

Accepted: October 20, 2019

Published: October 23, 2019

Copyright $\odot 2019$ by author(s) and Scientific Research Publishing Inc. This work is licensed under the Creative Commons Attribution International License (CC BY 4.0).

http://creativecommons.org/licenses/by/4.0/

\begin{abstract}
Sepsis has been redefined as a disorder of host response to infection, systemic circulation and cell/metabolic abnormalities. Exosomes are small $(30-150$ $\mathrm{nm}$ ) vesicles produced by all cells under physiological and pathological conditions, with the potential to transfer proteins, lipids, small RNAs, messenger RNAs, or DNA between cells. Exosomes are natural cargoes for proteins, carbohydrates, nucleic acids and lipids. Exosomes play a central role in cellular communication and contribute to many pathophysiological processes, including immune responses and tumor progression. Exosomes have made great progress in many subject areas, and their potential role in sepsis is now being explored. In this review, several topics are mentioned. Firstly, we discuss the biological characteristics and functions of exosomes. Next, we focus on the diagnostic and therapeutic potential of exosomes in sepsis. Finally, we discuss some of the problems encountered by the current exosomes research institute. Therefore, the exosomes with combined diagnostic and therapeutic functions play a huge clinical application for the future research in sepsis.
\end{abstract}

\section{Keywords}

Exosomes, Sepsis, Biological Function, Targeted Vector, Inflammation

\section{Introduction}

Exosomes are natural carriers of many signaling molecules, including lipids, proteins, DNA, mRNA, miRNA, and siRNA. They can smoothly pass through the circulation without degration by enzymes and thus transmit important mediators between cells [1]. Multi-functional circulating exosomes with various subtypes have been identified in many lesions such as cardiovascular, infectious ${ }^{\star} \mathrm{Co}$-first author. 
and autoimmune diseases. In addition, exosomes are also involved in adaptive immune response through the regulation of antigen presentation [2]. Sepsis remains a global medical problem, early diagnosis of which can inhibit its progression and improve outcomes [3]. However, the initiation or suspension of clinical interventions is still suffering from the lack of markers with high sensitivity and specificity. Accumulating evidence suggests that exosomes can be served as an attractive candidate for the treatment of sepsis. This review summarizes the biological behavior and application of exosomes [4].

\section{Formation and Composition of Exosomes}

\subsection{Formation of Exosomes}

Exosomes are small vesicles covered by plasma membrane [5]. The formation process of exosomes is complex and orderly. The intravesicular membrane is firstly inwardly depressed to form luminal vesicles, then multivesicular bodies are formed. When these polyvesicles are fused with lysosomes, they are degraded or recirculated and fused to the membrane, and then induced by endosomal sorting complex required for transport (ESCRT). The internal buds form granular vesicles, which are released into the extracellular environment and called exosomes [6].

\subsection{Composition of Exosomes}

Exosomes are mainly composed of lipids, proteins, mRNA, miRNAs, and long non-coding RNAs (lncRNAs) [7]. These components are essential for the unique biological functions of exosomes. The hydrophilic and lipophilic outer shell of exosomesis valuable in shuttling through hydrophilic and hydrophobic structures in the body fluid circulation [8].Nucleic acids, including mRNA, microRNA, and lncRNA, can be absorbed by the recipient cells through fusion with the target cell membrane, thereby activating the signaling pathway and controlling the protein expression [9]. A variety of protein components on the surface of exosomes such as (CD9, CD63, CD81), Alix, HSP70, HSP90 and GTPase have a labeling effect.

\subsection{Biological Roles in Exocytosis and Sepsis}

The content function of the exosomes and the mechanical properties of the membrane are being unveiled [10]. The exosomal function of different subpopulations varies between different donor/recipient cells and the tissue microenvironment. Under the influence of pathophysiological factors, donor cells load specific cargoes such as functional RNAs (miRNAs and mRNAs) and proteins into exosomes. Exosomes transport these cargoes to the recipient cells, causing subsequent genetic and phenotype changes [11]. The intercellular communication mediated by exosomes in sepsis is mainly through activation of target cell surface receptors, which induces cells to cope with changes in the external environment. After fusion with the recipient cells, the contents of the vesicles, such 
as microRNAs (miRNAs) or mRNAs and proteins, are transported to the cytoplasm [12]. Table 1 identifies the current exosomes with diagnostic value for sepsis in the study of exosomes.

As long as the donor cells are free of apoptosis and necrosis in the body, the exosomes secreted by it can persist in body fluids and maintain a stable concentration.

As donor cells, whatever conditions, can secrete exosomes, the concentration of which remains steady. These unique features of exosomes make them ideal carriers for anti-sepsis drugs [13].

\section{Exosomes and Sepsis}

\subsection{Exosomes Participate in the Onset Process of Sepsis}

Sepsis is defined as a life-threatening organ dysfunction caused by the host's dysregulation of immune response. However, our current understanding of its process, including early diagnosis, treatment, and prognosis evaluation, is still

Table 1. Exosome in body fluids as biomarkers of sepsis.

\begin{tabular}{|c|c|c|}
\hline $\begin{array}{l}\text { Associated Protein, } \\
\text { mRNAs or miR }\end{array}$ & Findings & Effects \\
\hline $\operatorname{miR}-15 \mathrm{a}$ & $\begin{array}{l}\text { Differentially expressed } \\
\text { in adult a neonatal sepsis }\end{array}$ & $\begin{array}{l}\text { Inhibits angiogenesis through } \\
\text { direct targeting of VEGF and FGF [33] }\end{array}$ \\
\hline $\operatorname{miR}-16 a$ & $\begin{array}{l}\text { in mice exposed } \\
\text { to lipopolysaccharides }\end{array}$ & $\begin{array}{l}\text { expression was shown to be } \\
\text { up-regulated Following CLP [34] }\end{array}$ \\
\hline $\operatorname{miR}-17$ & $\begin{array}{l}\text { in the whole blood } \\
\text { of mice after CLP }\end{array}$ & $\begin{array}{l}\text { were significantly up-regulated } \\
\text { in the microarray analysis } \\
\text { in mice subcutaneously [35] }\end{array}$ \\
\hline $\mathrm{miR}-20 \mathrm{a} / \mathrm{b}$ & $\begin{array}{l}\text { in the whole blood } \\
\text { of mice after CLP }\end{array}$ & $\begin{array}{l}\text { were significantly up-regulated } \\
\text { in the microarray analysis } \\
\text { in mice subcutaneously [35] }\end{array}$ \\
\hline $\operatorname{miR}-21$ & in late sepsis of mice & $\begin{array}{l}\text { with higher mortality in } \\
\text { LPS-peritonitis model [36] }\end{array}$ \\
\hline $\operatorname{miR}-146 a$ & patients with severe sepsi & $\begin{array}{l}\text { Predicted mortality and } \\
\text { treatment outcomes induced } \\
\text { by severe sepsis and sepsis. }\end{array}$ \\
\hline $\operatorname{miR}-150$ & in septic patients & $\begin{array}{l}\text { associated with survival rate in } \\
\text { patients with sepsis [37] }\end{array}$ \\
\hline $\operatorname{miR}-195$ & mice with CLP & $\begin{array}{l}\text { only significantly expressed } \\
\text { in the CLP model }\end{array}$ \\
\hline miR-223 & $\begin{array}{l}\text { patients with mild sepsis } \\
\text { severe sepsis and septic shock }\end{array}$ & $\begin{array}{c}\text { as novel diagnostic } \\
\text { biomarkers of sepsis [38] }\end{array}$ \\
\hline ATF3 & mice & an interesting sepsis-AKI biomarker [39] \\
\hline SPTLC3 & sepsis patient & $\begin{array}{l}\text { potential classifier to monitor clinical } \\
\text { progression of sepsis }[40]\end{array}$ \\
\hline
\end{tabular}


unclear. Almost all cells secrete exosomes, which are present throughout the body fluid circulation and mediate many aspects of disease development and progression by mediating cell-to-cell signaling [14] The currently evolving biotechnology of nanotechnology and genomics and proteomics provide the directions to target therapeutic agents in septic patients (Table 2).

In the setting of activation and apoptosis, exosomes are released and express specific membrane epitopes as their parental cells. The prospect for exosomes use in septic patients is bright, ranging from rapid and precise diagnostics [15]. Platelet-derived exosomes are isolated from patients with sepsis. These exosomes can produce oxidative enzymes in vascular endothelial cells and smooth muscle cells, induce apoptosis of vascular cells, suggesting a process of sepsis and septic shock. Platelet-derived exosomes may mediate vascular dysfunction through redox signaling pathways. During sepsis, platelets exposed to NO (nitric oxide) donors and LPS (lipopolysaccharide) secrete exosomes that activate caspase-3 and produce superoxide, NO and peroxynitrite. The base anion induces apoptosis, suggesting that platelet-derived exosomes can mediate vascular injury in a pathological, rather than physiological, environment. The anti-apoptotic effect

Table 2. Exosomes as therapeutic drug carriers and delivery vehicle.

\begin{tabular}{|c|c|c|}
\hline $\begin{array}{l}\text { Associated Protein, } \\
\text { mRNAs or miR }\end{array}$ & Findings & Effects \\
\hline miR-26b & mice with CLP & $\begin{array}{l}\text { affected the antiviral } \\
\text { response of the host }\end{array}$ \\
\hline miR-27a & $\begin{array}{l}\text { in the lungs } \\
\text { of septic mice }\end{array}$ & $\begin{array}{l}\text { up regulated in the } \\
\text { progression to shock }\end{array}$ \\
\hline miR-34a & in murine sepsis & $\begin{array}{l}\text { Regulate vascular } \\
\text { endothelial cell senescence }\end{array}$ \\
\hline $\mathrm{miR}-106 \mathrm{a} / \mathrm{b}$ & $\begin{array}{l}\text { in whole } \\
\text { blood of mice }\end{array}$ & $\begin{array}{l}\text { Promote phagocytosis of macrophages } \\
\text { by targeting SIRPa [41] }\end{array}$ \\
\hline miR-126 & in murine sepsis & $\begin{array}{l}\text { Attenuates the increase in plasma } \\
\text { levels of cytokines and } \\
\text { chemokines induced by sepsis }\end{array}$ \\
\hline NADPH oxidase & $\begin{array}{c}\text { patients with } \\
\text { diagnosis of septic } \\
\text { shock }\end{array}$ & $\begin{array}{c}\text { Improve dysfunction of heart and } \\
\text { papillary muscles in } \\
\text { patients with sepsis }[42]\end{array}$ \\
\hline miR-223 & in CLP mice & $\begin{array}{l}\text { play an important role in MSC-induced } \\
\text { cardioprotection in sepsis [43] }\end{array}$ \\
\hline MFG-E8 & rats by CLP & $\begin{array}{l}\text { Reduce the level of inflammatory } \\
\text { cytokines and increase the survival } \\
\text { rate of experimental animals [44] }\end{array}$ \\
\hline ADMSC & $\begin{array}{l}\text { patients with } \\
\text { diagnosis of } \\
\text { septic shock }\end{array}$ & $\begin{array}{l}\text { Improve dysfunction of heart and papillary } \\
\text { muscles in patientswith sepsis }[45]\end{array}$ \\
\hline
\end{tabular}

$\mathrm{miR}=$ microRNA, NADPH oxidase $=$ Nicotinamide-adenine dinucleotide-phosphate hydrogen oxidase, MFG-E8 = Milk-fat-globule epidermal-growth factor-factor VIII, ADMSC = Adipose-derived mesenchymal stem cell. 
of plasma-derived circulating exosomes on T lymphocytes in patients with sepsis can down-regulate the mRNA and protein levels of pro-apoptotic genes, and up-regulate the mRNA and protein levels of anti-apoptotic genes. Finally, it inhibits apoptosis of septic cells. These findings suggest that tissue vascular injury, apoptosis, and inflammatory responses in sepsis/septic shock are closely related to exosomes released by various effector cells in vivo [16].

\subsection{Exosomes Can Be Used as Biomarkers for the Diagnosis of Sepsis}

The high mortality rate of sepsis is closely related to complications, and sepsis cardiomyopathy is the main complication. In sepsis, the vascular endothelial physiology changes due to damage to the cardiovascular system, such as decreased $\mathrm{Ca}^{2+}$ response, mitochondrial dysfunction, and decreased $\beta$-adrenergic receptor response. Exosomes play an important role in the pathophysiology of the disease. When platelets are activated in sepsis, exosomes containing high concentrations of NADPH are released into the blood vessels of the heart, leading to cardiac function damage and failure.

Exosomes are released from the cells into the blood circulation. By detecting the content of some exosomes-including proteins and RNA in the body fluids, some diseases can be predicted before onset of clinical symptoms [17]. There was a highly significant correlation between the transit of exosomes-derived miRNAs and inflammatory responses, oxidative stress, and cell cycle regulation in patients with septic shock [18]. Exosomes can be detected in the setting of trauma and stress and maintain a certain concentration level even in lethal illness. From organ dysfunction to failure, exosomes are likely to play a monitoring and regulatory role, and also play an important role in predicting the outcome of the disease. Exosomal expression can be detected in sepsis. When animals are exposed to Gram-negative or Gram-positive infections, miRNA-16, miRNA-17, miRNA-20a, miRNA-20b, miRNA-26a and miRNA-26b can be abnormally elevated [19]. The plasma expression levels of miR-15a, miR-27a and miR-34a in exosomes are also closely related to the severity of sepsis development. These expressions of miRNA can be consistent with the changes of patients with sepsis. The level of miRNA in the plasma of patients with severe sepsis complicated with shock may change, which may provide more value for further study of the pathogenesis of sepsis endothelial dysfunction.

To this end, if the expression of miRNA is quantified, foreign miRNA expression can be used as a good biomarker for evaluating, monitoring and optimizing intensive treatment of sepsis in future critically ill patients.

\subsection{Exosomes Are Expected to Be a New Treatment for Sepsis}

Exosomes have the biological activity of substance transfer between cells, with the great potential of becoming therapeutic drug carriers. Exosomes can act as a mediator between cells and organs, regulating the biological activities of various substances involved in communication and signaling between cells. By upregu- 
lating miR-21 to increase its expression, it can reduce apoptosis and reduce the production of pro-inflammatory factors. Protecting organ damage in local and distal areas of sepsis may be a potential treatment for sepsis [20]. As an important inclusion in exosomes, miRNA is involved in the regulation of each cellular process. Their expression changes are related to the occurrence, development and repair of many diseases and are important regulators in physiological and pathological processes. MiR-21 may act as a protective molecular medium between damaged tissues and organs. It is expected to be a targeted treatment for sepsis.

MiR-146a enhances the effect of IL- $1 \beta$ on macrophage anti-sepsis infection. MiR-146a is a relatively important anti-inflammatory miRNA, and this exosome MiR-146a is greatly up-regulated due to inflammatory irritation.MiR-146a improves sexual performance and improves survival in mice with sepsis [21]. Although the mechanism for this study has not yet been fully elucidated, it can provide a new treatment for inflammatory disorders.MiR-145 can ameliorate sepsis-induced lung injury by inhibiting TGFBR2 signaling, and attenuate LPS-induced inflammation in mice by down-regulating IL-2 and TNF- $\alpha$ secretion, The overall survival rate of sepsis mice with lung injury was prolonged [22].

The circulating exosomes are rich in various types of biomolecules, affecting myocardial cell function, reducing the degree of myocardial infarction, reducing myocardial ischemia-reperfusion injury, and promoting myocardial regeneration and repair. And it is expected to be a specific biomarker for cardiovascular disease diagnosis, risk stratification and prognosis [23].

The use of proteins and nucleic acid components in exosomes as drug carriers and targeting tools for the treatment of sepsis is still being studied and discovered. The above studies suggest that it is effective to increase the content of some protective exosomes, thus avoiding the occurrence of multiple organ failure in sepsis.

\subsection{Exosomes Play a Role in Important Organ Damage in Patients with Sepsis}

Recently, sepsis has been redefined as a disorder of host response to infection, systemic circulation and cell/metabolic abnormalities, and its severity and clinical treatment depend largely on the organ dysfunction state of the patient. Every time an organ failure occurs, the probability of death will increase significantly [24]. Exosomes are released at different concentrations in healthy subjects and diseased populations, and the concentrations released into the circulation in different diseases are also different. Intratracheal instillation of extracellular vesicles derived from bone marrow mesenchymal stem cells can alleviate lung inflammation and edema caused by acute lung injury by inducing expression of keratinocyte growth factor [25]. The plasma concentrations of N-terminal B-type natriuretic peptide (NT-proBNP) and hypersensitive troponin $\mathrm{T}$ (hs-cTnT) in circulating blood in patients with severe sepsis or septic shock can follow the occur- 
rence of acute myocardial infarction, therefore, exosomes can be used as a multifunctional clinical indicator of early ischemic myocardial injury in intensive care [26].

Zhou found in the experiment that exosomes miR-126-5p and 3p can inhibit LPS-induced human microvascular endothelial cells (HMVECs) high mobility group protein b1 (HMGB1) and vascular cell adhesion molecule 1 (VCAM1) levels, It was confirmed that the use of EPR exosomes to deliver miR-126 can prevent microvascular dysfunction, attenuate the increase in plasma cytokine and chemokine levels induced by sepsis, inhibit lung and renal vascular leakage in vital organs, and improve the survival rate of mice with sepsis [27]. In the mouse kidney ischemia/reperfusion injury model, the level of urinary extracellular ATF3 (activating transcription factor 3) was detected to be higher than normal before serum creatinine concentration had increased [28]. This finding suggests that extracellular ATF3 is more sensitive as a biomarker in early acute kidney injury than traditional clinical biomarkers, suggesting that exosomes are expected to be an effective tool for the diagnosis/treatment of early acute kidney injury in further studies.

\section{Current Problems}

However, there are many problems and challenges in the study of exosomes. How to separate pure exosomes from various body fluids is a key issue. Presently, exosome extraction methods are mainly in five categories, namely, ultracentrifugation, precipitation, immunoadsorption, ultrafiltration, and microfluidic separation techniques [29]. Although differential centrifugation and ultracentrifugation are the most commonly used techniques in clinical laboratories. However, this method has certain limitations due to its protein contamination and yield problems [30]. New methods such as density gradient centrifugation, while overcoming the above limitations, are complicated in steps, and the experimental process takes a long time and cannot be applied to the clinic. There are many reports on the relationship between extracellular vesicle biomarkers and various diseases. However, the results of individual studies vary widely, probably due to the differences of exosome in extraction and purification methods [31]. Due to the complex structure, variable composition and versatility of exosomes, exosomes in these natural states are difficult to be used as targeting targets for drugs. At the same time, most of these studies are preliminary, only in animal models, and further research is needed to translate into clinical applications.

\section{Conclusion and Outlook}

Although the pathogenesis and clinical treatment of sepsis have made great progress, the mortality rate of sepsis has not decreased [32]. So far, some indicators of sepsis have been used only to determine the presence of organ failure and to assess the patient's clinical outcome. Exosomes can play a huge potential as a disease-specific biomarker and a carrier for the treatment of sepsis/septic shock. 
It is a hot research topic to make full use of the unique biological function of exosomes and to study and elucidate the mechanism of sepsis from different levels such as cells and molecules. It will provide new help for targeted specific treatment of sepsis/infectious shock.

\section{Acknowledgements}

This work is supported by National Natural Science Foundation of China (81760353), Science and Technology Project of Henan Province (No. 172102 310627), Major Science research Project of high Education of Henan Province (No. 16A320065, 20A320086), Major Science research Project of Zhengzhou Railway Vocational and Technical College (No. 2019KY002).

\section{Conflicts of Interest}

The authors declare no conflicts of interest regarding the publication of this paper.

\section{References}

[1] Yanez-Mo, M., Siljander, P.R., Andreu, Z., et al. (2015) Biological Properties of Extracellular Vesicles and Their Physiological Functions. Journal of Extracellular Vesicles, 4, 27065-27066.

[2] De Toro, J., Herschlik, L., Waldner, C., et al. (2015) Emerging Roles of Exosomes in Normal and Pathological Conditions: New Insights for Diagnosis and Therapeutic Applications. Frontiers in Immunology, 6, 203. https://doi.org/10.3389/fimmu.2015.00203

[3] Manu, S., Gary, S.P., Mitchell, L.L., et al. (2016) Developing a New Definition and Assessing New Clinical Criteria for Septic Shock: For the Third International Consensus Definitions for Sepsis and Septic Shock (Sepsis-3). JAMA, 315, 762-774. https://doi.org/10.1001/jama.2016.0289

[4] Terrasini, N. and Lionetti, V. (2017) Exosomes in Critical Illness. Critical Care Medicine, 45, 1054-1060. https://doi.org/10.1097/CCM.0000000000002328

[5] Johnstone, R.M., Adam, M., Hammond, J.R., et al. (1987) Vesicle Formation during Reticulocyte Maturation-Association of Plasma-Membrane Activities with Released Vesicles (Exosomes). Journal of Biological Chemistry, 262, 9412-9420.

[6] Buschow, S.I., Nolte-'T Hoen, E.N.M., van Niel, G., et al. (2009) MHC II in Dendritic Cells Is Targeted to Lysosomes or T Cell-Induced Exosomes via Distinct Multivesicular Body Pathways. Traffic, 10, 1528-1542. https://doi.org/10.1111/j.1600-0854.2009.00963.x

[7] Shahabipour, F., Barati, N., Johnston, T.P., et al. (2017) Exosomes: Nanoparticulate Tools for RNA Interference and Drug Delivery. Journal of Cellular Physiology, 232, 1660-1668. https://doi.org/10.1002/jcp.25766

[8] Ren, J., He, W., Zheng, L., et al. (2016) From Structures to Functions: Insights into Exosomes as Promising Drug Delivery Vehicles. Biomaterials Science, 4, 910-921. https://doi.org/10.1039/C5BM00583C

[9] Valadi, H., Ekstrom, K., Bossios, A., et al. (2007) Exosome-Mediated Transfer of mRNAs and microRNAs Is a Novel Mechanism of Genetic Exchange between Cells. Nature Cell Biology, 9, 654-672. https://doi.org/10.1038/ncb1596 
[10] Lucia, P., Andrea, Z. and Annalisa, R. (2018) Biophysical Properties of Extracellular Vesicles in Diagnostics. Biomarkers in Medicine, 12, 383-391. https://doi.org/10.2217/bmm-2017-0458

[11] Wu, J., Wang, Y. and Li, L. (2017) Functional Significance of Exosomes Applied in Sepsis: A Novel Approach to Therapy. Biochimica et Biophysica Acta-Molecular Basis of Disease, 1863, 292-297. https://doi.org/10.1016/j.bbadis.2016.10.024

[12] Srinivasan, S., Vannberg, F.O. and Dixon, J.B. (2016) Lymphatic Transport of Exosomes as a Rapid Route of Information Dissemination to the Lymph Node. Scientific Reports, 6, Article No. 24436. https://doi.org/10.1038/srep24436

[13] Conlan, R.S., Pisano, S., Oliveira, M.I., et al. (2017) Exosomes as Reconfigurable Therapeutic Systems. Trends in Molecular Medicine, 23, 636-650.

https://doi.org/10.1016/j.molmed.2017.05.003

[14] Takahashi, A., Okada, R., Nagao, K., et al. (2017) Exosomes Maintain Cellular Homeostasis by Excreting Harmful DNA from Cells. Nature Communications, 8, 15287. https://doi.org/10.1038/ncomms 15287

[15] Pierre, R., Johannes, Z. and Susanne, D. (2018) Extracellular Vesicles as Markers and Mediators in Sepsis. Theranostics, 8, 3348-3365.

https://doi.org/10.7150/thno.23453

[16] Gambim, M.H., Do Carmo, A.D.O., Marti, L., et al. (2007) Platelet-Derived Exosomes Induce Endothelial Cell Apoptosis through Peroxynitrite Generation: Experimental Evidence for a Novel Mechanism of Septic Vascular Dysfunction. Critical Care, 11, R107. https://doi.org/10.1186/cc6133

[17] Revenfeld, A.L.S., Baek, R., Nielsen, M.H., et al. (2014) Diagnostic and Prognostic Potential of Extracellular Vesicles in Peripheral Blood. Clinical Therapeutics, 36, 830-846. https://doi.org/10.1016/j.clinthera.2014.05.008

[18] Juliana, M.R., Ludmila, R.P.F., Gustavo, H.E., et al. (2018) Exosomes from Patients with Septic Shock Convey miRNAs Related to Inflammation and Cell Cycle Regulation: New Signaling Pathways in Sepsis? Critical Care (London, England), 22, 68. https://doi.org/10.1186/s13054-018-2003-3

[19] Wu, S., Yang, J.C., Rau, C., et al. (2013) Profiling Circulating microRNA Expression in Experimental Sepsis Using Cecal Ligation and Puncture. PLoS ONE, 8, e77936. https://doi.org/10.1371/journal.pone.0077936

[20] Jia, P., Wu, X., Dai, Y., et al. (2017) MicroRNA-21 Is Required for Local and Remote Ischemic Preconditioning in Multiple Organ Protection against Sepsis. Critical Care Medicine, 45, E703-E710. https://doi.org/10.1097/CCM.0000000000002363

[21] Song, Y., Dou, H., Li, X., et al. (2017) Exosomal miR-146a Contributes to the Enhanced Therapeutic Efficacy of Interleukin-1-Primed Mesenchymal Stem Cells against Sepsis. Stem Cells, 35, 1208-1221. https://doi.org/10.1002/stem.2564

[22] Cao, X.H., et al. (2019) MiR-145 Negatively Regulates TGFBR2 Signaling Responsible for Sepsis-Induced Acute Lung Injury. Biomedicine \& Pharmacotherapy, 111, 852-858. https://doi.org/10.1016/j.biopha.2018.12.138

[23] Ebru, K., Steffen, U.E., Julia, H., et al. (2018) Extracellular Vesicles: Packages Sent with Complement. Frontiers in Immunology, 9, 721. https://doi.org/10.3389/fimmu.2018.00721

[24] Schmoch, T., et al. (2017) New Sepsis-3 Definition: Do We Have to Treat Sepsis before We Can Diagnose It from Now on? Der Anaesthesist, 66, 614-621.

[25] Zhu, Y., Feng, X., Abbott, J., et al. (2014) Human Mesenchymal Stem Cell Microvesicles for Treatment of Escherichia coli Endotoxin-Induced Acute Lung Injury in 
Mice. Stem Cells, 32, 116-125. https://doi.org/10.1002/stem.1504

[26] Masson, S., Caironi, P., Fanizza, C., et al. (2016) Sequential N-Terminal Pro-B-Type Natriuretic Peptide and High-Sensitivity Cardiac Troponin Measurements during Albumin Replacement in Patients with Severe Sepsis or Septic Shock. Critical Care Medicine, 44, 707-716.

[27] Zhou, Y., et al. (2018) Exosomes from Endothelial Progenitor Cells Improve the Outcome of a Murine Model of Sepsis. Molecular Therapy. The Journal of the American Society of Gene Therapy, 26, 1375-1384. https://doi.org/10.1016/j.ymthe.2018.02.020

[28] Chen, H., Lai, P., Lan, Y., et al. (2014) Exosomal ATF3 RNA Attenuates Pro-Inflammatory Gene MCP-1 Transcription in Renal Ischemia-Reperfusion. Journal of Cellular Physiology, 229, 1202-1211. https://doi.org/10.1002/jcp.24554

[29] Hyungsoon, I., Cesar, M.C., et al. (2018) New Technologies for Analysis of Extracellular Vesicles. Chemical Reviews, 118, 1917-1950. https://doi.org/10.1021/acs.chemrev.7b00534

[30] Lotvall, J., Hill, A.F., Hochberg, F., et al. (2014) Minimal Experimental Requirements for Definition of Extracellular Vesicles and Their Functions: A Position Statement from the International Society for Extracellular Vesicles. Journal of Extracellular Vesicles, 3, 26913. https://doi.org/10.3402/jev.v3.26913

[31] Barile, L. and Vassalli, G. (2017) Exosomes: Therapy Delivery Tools and Biomarkers of Diseases. Pharmacology \& Therapeutics, 174, 63-78. https://doi.org/10.1016/j.pharmthera.2017.02.020

[32] Angus, D.C. and van der Poll, T. (2013) Severe Sepsis and Septic Shock. The New England Journal of Medicine, 369, 2063. https://doi.org/10.1056/NEJMc1312359

[33] Wang, X.L., et al. (2015) miR-15a/16 Are Upreuglated in the Serum of Neonatal Sepsis Patients and Inhibit the LPS-Induced Inflammatory Pathway. International Journal of Clinical and Experimental Medicine, 8, 5683-5690.

[34] Hsieh, C.-H., et al. (2012) Whole Blood-Derived microRNA Signatures in Mice Exposed to Lipopolysaccharides. Journal of Biomedical Science, 19, Article No. 69. https://doi.org/10.1186/1423-0127-19-69

[35] Wu, S.C., Yang, J.C., Rau, C.S., Chen, Y.C., Lu, T.H., et al. (2013) Profiling Circulating microRNA Expression in Experimental Sepsis Using Cecal Ligation and Puncture. PLOS ONE, 8, e77936. https://doi.org/10.1371/journal.pone.0077936

[36] Rebecca, E.B., Daniel, J.C., Lindsey, R., et al. (2016) Anti-Inflammatory Effects of miR-21 in the Macrophage Response to Peritonitis. Journal of Leukocyte Biology, 99, 361-371. https://doi.org/10.1189/jlb.4A1014-489R

[37] Christoph, R., Mark, L., David, V.C., et al. (2013) Circulating microRNA-150 Serum Levels Predict Survival in Patients with Critical Illness and Sepsis. PLoS ONE, 8, e54612. https://doi.org/10.1371/journal.pone.0054612

[38] Wang, H.J., Zhang, P.J., Chen, W.J., Feng, D., Jia, Y.H. and Xie, L.X. (2012) Four Serum microRNAs Identified as Diagnostic Biomarkers of Sepsis. The Journal of Trauma and Acute Care Surgery, 73, 850-854. https://doi.org/10.1097/TA.0b013e31825a7560

[39] Tanaporn, P., Wiwat, C., Poorichaya, S., et al. (2017) Urinary Exosomal Activating Transcriptional Factor 3 as the Early Diagnostic Biomarker for Sepsis-Induced Acute Kidney Injury. BMC Nephrology, 18, 10. https://doi.org/10.1186/s12882-016-0415-3

[40] Xu, Y., Ku, X., Wu, C., Cai, C., Tang, J. and Yan, W. (2018) Exosomal Proteome 
Analysis of Human Plasma to Monitor Sepsis Progression. Biochemical and Biophysical Research Communications, 499, 856-861.

https://doi.org/10.1016/j.bbrc.2018.04.006

[41] Zhu, D., Pan, C., Li, L., et al. (2013) MicroRNA-17/20a/106a Modulate Macrophage Inflammatory Responses through Targeting Signal-Regulatory Protein $\alpha$. The Journal of Allergy and Clinical Immunology, 132, 426-436.e8.

https://doi.org/10.1016/j.jaci.2013.02.005

[42] Luciano, C.P.A., Mariano, J., Vera, P., et al. (2007) Platelet-Derived Exosomes from Septic Shock Patients Induce Myocardial Dysfunction. Critical Care (London, England), 11, R120. https://doi.org/10.1186/cc6176

[43] Wang, X., Gu, H., Qin, D., et al. (2015) Exosomal miR-223 Contributes to Mesenchymal Stem Cell-Elicited Cardioprotection in Polymicrobial Sepsis. Scientific Reports, 5, Article No. 13721. https://doi.org/10.1038/srep13721

[44] Miksa, M., Wu, R., Dong, W., Das, P., Yang, D. and Wang, P. (2006) Dendritic Cell-Derived Exosomes Containing Milk Fat Globule Epidermal Growth Factor-Factor VIII Attenuate Proinflammatory Responses in Sepsis. Shock, 25, 586-593. https://doi.org/10.1097/01.shk.0000209533.22941.d0

[45] Chang, C.L., Sung, P.H., Chen, K.H., et al. (2018) Adipose-Derived Mesenchymal Stem Cell-Derived Exosomes Alleviate Overwhelming Systemic Inflammatory Reaction and Organ Damage and Improve Outcome in Rat Sepsis Syndrome. American Journal of Translational Research, 10, 1053-1070. 